\title{
SYMPOSIUM ON THE NEUROHYPOPHYSIS
}

A $\mathrm{N}$ international symposium on the neurohypophysis, arranged by the Colston Research Society and the University of Bristol, was held in Bristol during April 9-12. A generous grant from the Wellcome Trust made it possible to extend invitations to workers from the United States and Canada. Prof. H. Heller (Bristol), director of the symposium, welcomed the participants and pointed out that this was the first international meeting entirely devoted to the subject. He reminded his audience that it was also a scientific anniversary, since it was fifty years ago that Sir Henry Dale had discovered the oxytocic effect of posterior pituitary extracts.

Sir Henry Dale then opened the symposium. In a fascinating survey of the history of the subject, he recalled that the first evidence for the presence of a biologically active principle in the pituitary gland was obtained by G. Oliver, a Harrogate physician who, having observed the pressor effect of adrenal extract, proceeded in collaboration with E. A. Schäfer to test extracts of other endocrine glands on the blood pressure of anæsthetized animals. Sir Henry then mentioned his early experiments on the chemistry of the posterior pituitary principles, which already then-in 1909-suggested that they were peptides, and described the first separation of oxytocin from vasopressin by $H$. W. Dudley in his laboratory, work which found its brilliant conclusion only recently in the establishment of the chemical constitution of the active peptides by V. du Vigneaud and his co-workers. Similarly, the old difficulty of understanding how an organ consisting of neuroglia and nerve fibres could produce hormones has only recently been overcome by including the neurosecretory cells in the hypothalamus in the neurohypophysial system. Based on these developments and on recent unpublished work by Dr. Catherine Hebb, Sir Henry drew an interesting parallel between the results of pituitary stalk section and the cutting of a cholinergic nerve: in both cases the active principle(s) disappears rapidly distal to the cut and accumulates proximally.

The rest of the session was devoted to the morphological aspect of neurohypophysial secretion. Prof. W. Bargmann (Kiel), reviewing the relation between neurohypophysial structure and function, stressed the parallelism between the demonstrable amounts of neurosecretory material in the neurohypophysis and its hormone content in a variety of physiological and experimental conditions. He discussed the site of origin of the neurohypophysial hormones and mentioned the unpublished finding of W. Hild that pituicytes in tissue culture are unable to elaborate the hormones. These cells may, however, be concerned in their release. In conclusion, Prof. Bargmann directed attention to the fact that neurosecretory fibres also enter the pars tuberalis and pars intermedia. In the discussion, Prof. B. Hanström (Lund) mentioned the rarity of such fibres in the pars intermedia of some mammalian forms, a finding with which Prof. Bargmann agreed. Dr. H. Rodeck (Düsseldorf) gave new evidence for the lack of neurosecretory material in new-born animals and in infants, and Profs. C. Fromageot (Paris) and H. B. van Dyke (New York) agreed that no firm statement can as yet be made as to the chemical nature of the neurosecretory substance.

Prof. Hanström, in a comprehensive and stimulating survey, showed the close similarity in the arehitecture of the neurosecretory systems of invertebrates and vertebrates. Crustaceans and insects, for example, have not only neurosecretory cells in their brains but also specific storage organs for the neurosecretory material elaborated. In the discussion, Dr. P. A. Jewell (London) described the histological appearance of the neurohypophysis of dogs which have been continuously hydrated for ten days.

The day concluded by the annual reception of the Colston Research Society in the Great Hall of the University, at which the Lord Mayor, the ViceChancellor of the University and the immediate past-president of the Colston Research Society, the Bishop of Bristol, were present. The president of the Society, Prof. Macgregor Skene, explained the origin and purpose of the Colston Research Society, and Sir Lionel Whitby, the guest speaker, gave a masterly address on the importance of endocrinology in clinical medicine.

The second day of the symposium was opened with a paper by Prof. C. Fromageot (Paris). He and Dr. R. Acher have investigated the active protein which can be obtained from ox pituitary glands and have found that its pressor and oxytocic activities behave towards chemical and enzymatic agents exactly like the pure polypeptides. Mild processes like counter-current distribution and electrodialysis, which do not involve hydrolysis, dissociate the active protein into substances responsible for the oxytocic and pressor activities and at least one inert protein. This suggested the possibility of a differential release of the hormones in vivo. Prof. Fromageot adduced evidence for such difference in hormone release in lactating rats. Prof. H. Croxatto (Santiago, Chile) analysed the chemical and biological properties of polypeptides with posterior pituitary-like activities which can be obtained by the action of enzymes on blood proteins. Though similar in many ways, these artificial peptides differ in some respects from vasopressin and oxytocin. The paper gave rise to discussion on, among other topics, Prof. Croxatto's suggestion that his peptides may be connected with the 'unspecific' antidiuretic and oxytocic effects so frequently encountered in tests with biological material. The third paper of the morning was read by Prof. H. B. van Dyke (New York), who, with characteristic thoroughness and lucidity, reported on problems concerned with the storage and liberation of the neurohypophysial hormones. The relative distribution in the hypothalamic nuclei and the neural lobe differs from species to species; the dog's hypothalamus, for example, is much richer in vasopressin, whereas camel tissue contains more oxytocin. Depletion of hormones stored in the posterior lobe, if severe, affects both hormones, although the teleological requirement may be only for one. In lactating dogs both principles are depleted from the neural lobe, but the depletion of oxytocin is greater. Prof. van Dyke then adduced most interesting new evidence on two forms of vasopressin occurring in mammalian glands. Only hog extracts contain lysine vasopressin; all other mammalian extracts tested 
(including those of human glands) seem to contain arginine vasopressin, which has a relatively higher antidiuretic potency than hog vasopressin. In the discussion, Dr. S. J. Folley (Reading) and Prof. G. W. Harris (London) pointed out that differences in hormone ratios found during lactation in different species may be related to different suckling habits.

The afternoon session, under the chairmanship of Prof. J. M. Yoffey (Bristol), was occupied by papers on the metabolism and fate of the neurohypophysial principle. Prof. H. Heller (Bristol) surveyed the subject and queried the applicability of many in vitro experiments with body fluids and tissues. Recent results obtained in his laboratory (in collaboration with Dr. S. M. A. Zaidi, of Lahore) show that the kidneys and liver in the intact rat inactivate exogenous and endogenous vasopressin with very great rapidity. In the discussion, Dr. F. Gross (Basle) quoted sup. porting evidence, and Prof. Fromageot explained that there are three different chemical reactions conceivable by which vasopressin can be quickly inactivated. Prof. R. L. Noble (London, Ontario), in his paper on the excretion of posterior pituitary principles in the urine, described a new method for the extraction of vasopressin from body fluids which allows a consistent recovery of 85-90 per cent of added hormone. He then reported on the occurrence of antidiuretic activity in human urine in conditions like dehydration, fainting, emotional upsets and electro-convulsive therapy.

The third day of the symposium began with a paper by Dr. M. Ginsburg (Bristol), who described experiments which suggest that vasopressin may play a part in maintaining the blood pressure after hæmorrhage. Discussing a variety of stimuli to the neurohypophysis, he emphasized that stimuli for the release of hormones must be distinguished from those which lead to an increase of production of the active principles. He then described experiments in collaboration with Mrs. L. Brown, in which by means of injections of hypertonic solutions into the internal carotid they have unsuccessfully attempted to produce antidiuretic effects in the rat, and enumerated factors which might have prevented such responses. This led to a long discussion on the efficacy of osmotic stimuli to the neurohypophysis, in which Drs. P. A Jewell (London), M. Pickford (Edinburgh), D. F. Cole (Newcastle), H. E. de Wardener (London), J. C. Sloper (London), H. Croxatto (Santiago) and F. Morel (Paris) participated.

A paper read by Dr. B. Andersson (Stockholm) extended the field of the symposium in a most interesting manner by showing that electrical stimulation of certain areas of the hypothalamus by the elegant 'indirect' method developed by G. W. Harris, or by direct injection of hypertonic sodium chloride solution, induces polydipsia in the goat. This 'drinking area' overlaps partially with that from which antidiuresis can be elicited. This raises the interesting possibility of a dual role of the hypothalamic osmoreceptors in regulating both water intake and water output. Dr. B. A. Cross (Cambridge) pointed out that he has found in the rabbit that stimulation of the paraventricular nucleus results in the release of oxytocin, but that Dr. Andersson has shown for the first time that antidiuretic hormone also can be released by stimulating the same hypothalamic area. Dr. Mary Pickford (Edinburgh), in a paper with Dr. F. B. Brooks (Philadelphia), described experiments which make it possible that oxytocin, by influencing electrolyte excretion, has a physiological action on the kidney. This possibility had been envisaged in the rat by Dicker and Heller and Heller and Stephenson; but Pickford and Brooks have now shown that in certain circumstances oxytocin modifies renal sodium and potassium excretion in the dog also.

The afternoon session was devoted to papers on the mechanism of action of the antidiuretic hormone. Prof. H. Wirz (Basle), by accomplishing the astonishing feat of puncturing single distal tubules of the concentrating or diluting rat kidney and analysing the fluid obtained, has been able to support the concepts of H. W. Smith on the site of action of the antidiuretic hormone in the renal tubule. He agreed with Dr. W. H. Sawyer (New York), the following speaker, in postulating that the essential action of the hormone consists in altering the permeability of a section or of sections of the distal tubular epithelium to water. Both speakers also agreed in the revolutionary assumption that the antidiuretic hormone is not directly concerned in the elaboration of hypertonic urine. Equally interesting was Dr. Sawyer's suggestion that the increase in tubular water absorp. tion, which he has found to be caused in frogs by neurohypophysial extracts, is based on the same mechanism as their action on the frog's skin.

The first paper on the last day of the symposium was by Drs. S. J. Folley and A. T. Cowie (Reading), who gave an admirable survey of the relations of the neurohypophysial hormones to the mammary gland. The interesting concept was mentioned that the release of the lactogenic and galactopoietic factors from the anterior lobe may be controlled by oxytocin, thus uniting the main phases of lactation-milk secretion and milk ejection. Experiments by Folley and Benson relevant to this hypothesis are giving encouraging results. A vivid discussion, in which the chairman of the seasion, Sir Solly Zuckerman (Birmingham), Prof. G. W. Harris and Drs. M. Pickford, F. Stutinsky (Paris), I. Chester Jones (Liverpool) and J. C. Sloper took part, developed on the question of the reorganization of the cut pituitary stalk. A paper by R. J. Fitzpatrick (Bristol) on the relation of oxytocin to uterine function followed. He showed that different parts of the uterus vary quantitatively in their response to oxytocin. This was interpreted in relation to the requirements for sperm transport and the expulsion of the foetus at term. The third speaker of the morning, Dr. J. M. Walker (Oxford), described experiments with G. W. Bisset in which, utilizing a method for the extraction of oxytocin and vasopressin from blood, they have investigated the release of the hormone under the influence of drugs. He made the important point that pharmacologically the hypophysial synapse differs from that in peripheral ganglia.

The last session dealt 'with adrenocortical-neurohypophysial relationships. Dr. R. Gaunt (Summit, N.J.), after a critical review of the problems involved, reported on new work with C. W. Lloyd and J. J. Chart. Their most interesting finding perhaps is that hydrocortisone-like steroids either inhibit the release or facilitate the synthesis of vasopressin and of neurosecretory material.

Dr. I. Chester Jones (Liverpool) continued to unravel the relationship between the neurohypophysis and the adrenals by describing the morphological and functional changes in adrenalectomized rats with diabetes insipidus. Dr. F. Stutinsky then compared the effect of the ingestion of hypertonic salt solutions on the adrenal cortex of normal rats 
and animals with diabetes insipidus, and Dr. Lucie Arvy (Paris) showed slides which gave the first suggestion that the neurohypophysis is implicated in the osmoregulation of teleost fishes.

The pleasant atmosphere and the apparently general enjoyment in the symposium can be attributed not only to the restricted number of participants (nearly all of whom were actively engaged in research on its subject) but also to the excellent arrangements of the Colston Research Society, which housed all members in Manor Hall, a hall of residence of the University of Bristol. The scientific meetings were held in the same building, so that much unnecessary inconvenience and loss of time were avoided. The proceedings of the symposium will be published as Volume 8 of the "Colstion Papers". H. Heller

\section{EUROPEAN SEISMOLOGICAL COMMISSION \\ MEETINGS IN VIENNA}

$\mathrm{T}$ HE European Seismological Commission, a Commission set up by the Section for Seismology and the Physics of the Interior of the Earth of the International Union of Geodesy and Geophysics, met in the Institute of Physics of the University of Vienna during April 4-7 under the presidency of Prof. W. Hiller, of Stuttgart. The Commission had the support of Unesco, and nineteen countries were represented. Four topics were discussed : the organization and preparation for carrying out large explosions, particularly in Alpine regions, for seismic purposes; the progress achieved in the preparation of a European Earthquake Catalogue and a seismotectonic map of Europe; the progress made in the design and construction of seismographs, particularly those to be used to record near earthquakes, and the testing of such instruments; and microseisms.

The methods of seismic prospecting for minerals (particularly for possible oil-bearing structures) by letting off small quantities of explosives and receiving the reflected and refracted sound waves on geophones or seismographs are by now well known, and the subject has an extensive literature of its own. It was by this means that the British oilfield at Eakring was discovered. Only one explosion in Great Britain has been large enough to send waves down to penetrate all the layers of the Earth's crust, and this explosion was accidental-namely, the Burton-onTrent explosion of November 27, 1944. In $1909 \mathrm{~A}$. Mohorovičic found a discontinuity at the base of the continental layers of the Earth's crust in south-east Europe at a depth of $60 \mathrm{~km}$., now called the Mohorovičić discontinuity. Its depth varies over the Earth, but it is almost always present; in France it is estimated to be at a depth of $38 \mathrm{~km}$., and under the Central Appalachians in the United States it is $40-50 \mathrm{~km}$. The possible variation of the depth of the Mohorovičic discontinuity under mountain regions such as the Alps in Europe is particularly interesting, and it is proposed to try to find such depths by using the methods of seismic prospecting with sufficient quantities of explosives so that the $P$-waves which are generated will penetrate below the discontinuity. The time and place of the explosion, being known, will give fewer unknowns in the calculations than with natural earthquakes, and the arrival times of the reflected and refracted waves, being approx- imately known, will render possible the use of faster than normal paper speeds in the seismographs and thus greater accuracy in the time measurement. Moreover, since the explosion point is known, it will be possible to arrange the positions of the seismographs to advantage both in azimuth and distance.

The first experiments in western Europe will be carried out by the French during the second half of August 1956 at Briançon. The first explosions will be set off in the middle of a lake which is situated at a height of $2,500 \mathrm{~m}$. above sea-level, and there will be five successive explosions of $1,2,2,5$ and 10 tonnes. The first ones will give experience of the best methods, and the whole series will give an idea of the optimum or minimum quantity of explosive necessary for the purpose. The French will set up seismographs situated along two lines which will intersect at right angles at the lake. The explosions will also be recorded by seismographs in Germany, Italy and perhaps in Czechoslovakia. As soon as the results of this work have been studied, the French seismologists propose to make a further series of similar experiments from a lake situated $40-50 \mathrm{~km}$. to the east of the first one, so that records may be obtained over the same ground but in the reverse direction. This is so that true wave velocities may be determined in the manner usual in seismic prospecting. The second series of explosions will probably be held in 1957. As soon as the results of the first French experiments are known, similar explosion experiments will be made in the Eastern Alps, probably in the Hohe Tauern, east of Innsbruck in Austria, but these will not be possible this year.

Experiments in the U.S.S.R. along these lines have already taken place, organized by the Geophysical Institute of the U.S.S.R. Academy of Sciences under Academician G. A. Gamburtzev, the results being communicated to the Vienna meeting by Prof. E. F. Savarensky. The method used by the Russians is called the GSZ method and makes use of explosions of 50-300 kgm. of material. The distance between the explosion point and reception point may be up to $400 \mathrm{~km}$. The charges are usually placed in reservoirs, lakes or rivers and are exploded during meteorologically quiet times at night. The effective sensitivity of the reception devices is increased by properly regulated frequency ranges with a maximum amplification, by the increase of the general sensitivity of the equipment under a low level of internal noise and by use of methods of bunching reception. The registration of waves, including radiation of wavelength shorter than usually recorded hitherto, is effected by the use of many-channel stations which permits the most effective correlation methods. Receptors are arranged in different azimuths, and note is taken of the polarization of the oscillations. Different types of waves are distinguished (longitudinal, transverse and surface), as are also differences between single waves and waves resulting from complex interference. Separate crossings of profiles and also groups of reception points are used, the shot point being static.

In particular, large explosions have been made by these methods and for these purposes at Korkino near Chelyabinsk in the Ural Mountains, at Tula in the European part of the U.S.S.R. and in Central Asia. The GSZ method was used in pre-mountain and mountain regions of North Tien-Shan, in Western Turkmenia, in Pamiro-Altaisk and other regions. The section from south to north through the mountain ridges of the Kungey-Ala-Tau and Jan Karsky- 